\title{
Salt-tolerance Function in Halotolerant Bacteria from Coastal Soil and Sediment Present near Saltern Field of Hainan Island, China
}

\section{Yonggan Chen}

Hainan Tropical Ocean University

Zhenhua Zhang ( $\nabla$ zzh@nies.org)

Nanjing Institute of Environmental Sciences https://orcid.org/0000-0003-2714-0540

Hongwei Luo

Hainan Tropical Ocean University

Zhen Li

Hainan Tropical Ocean University

\section{Research Article}

Keywords: Salt-tolerance, coastal soils and sediments, saltern

Posted Date: April 13th, 2021

DOI: https://doi.org/10.21203/rs.3.rs-307487/v1

License: (c) (i) This work is licensed under a Creative Commons Attribution 4.0 International License. Read Full License 


\section{Salt-tolerance Function in Halotolerant Bacteria from Coastal Soil and Sediment Present near Saltern Field of Hainan Island, China}

Running title: salt-tolerance function in halotolerant bacteria from coastal soils and sediments

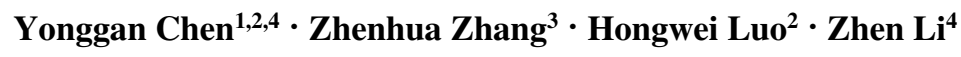

$\bowtie$ Zhenhua Zhang

zzh@nies.org

https://orcid.org/0000-0003-2714-0540

${ }^{1}$ Key laboratory of Utilization and Conservation for Tropical Marine Bioresources (Hainan Tropical Ocean University), Ministry of Education, Sanya 572022, China

${ }^{2}$ Hainan Key Laboratory for Conservation and Utilization of Tropical Marine Fishery Resources, Hainan Tropical Ocean University, Sanya 572022, China

${ }^{3}$ Key laboratory of Biosafety, Nanjing Institute of Environmental Sciences, Nanjing 210042, China

${ }^{4}$ College of Fisheries and Life Science, Hainan Tropical Ocean University, Sanya 572022, China 


\begin{abstract}
Understanding the salt-tolerance function in microbial communities may help illustrate the influences of salt concentration and other environmental factors on the soil biodiversity. Here, we combined high-throughput sequencing of $16 \mathrm{~S}$ rDNA and ITS to investigate the distribution and salt-tolerance function of microbial communities in coastal soils and sediments present near the Yinggehai saltern field of Hainan Island, China. The microbial communities in the soil and sediments of the land zone (YGHLS), the intertidal zone (YGHIS), and the inshore zone (YGHWS) were compared. PCoA of weighted and unweighted UniFrac distances showed the difference in soil microbial communities across the samples. ANOSIM analysis revealed that the three samples were separated from each other. Halomonas, Halobacillus, and Wallemia presented in the samples and accounted for $0.0335 \pm 0.0586 \%, 0.0241 \pm 0.0304 \%$, and $0.0308 \pm 0.0445 \%$ of the total microbial community. Relative abundance of $\mathrm{Na}^{+}: \mathrm{H}^{+}$antiporter, Trk system potassium uptake protein, and Kdp operon response regulator in the samples exceed $0.02 \%, 0.09 \%$, and $0.06 \%$ respectively. It revealed that the halotolerant bacteria of Yinggehai coastal soil and sediment mainly take the Trk system for salt-tolerance function.
\end{abstract}

Keywords Salt-tolerance $\cdot$ coastal soils and sediments $\cdot$ saltern 


\section{Introduction}

Island ecosystem is a unique and fragile ecosystem on earth. They provide special habitat for a wide variety of terrestrial and aquatic organisms and play important ecological and economic roles. Due to the high salt environment and other special environment factors, it owns abundant microbial genetic resources (Somboonna et al. 2012, Ng and Tan 2018, Sottorff et al. 2019). Characteristics of microbial community that exists in the coast near the saltern of an island is an interesting theme in ecology.

To assess the effects of hypersaline environment on microbial composition, many microbial biogeography studies examined coastal soils and sediments present in saltern fields. The phyla Proteobacteria, Firmicutes, and Actinobacteria were isolated from coastal solar salterns and revealed they have the ability to synthesize bioactive molecules (Boyadzhieva et al. 2018). Tang et al. (2011) reported 47 bacterial isolates either in the phylum Firmicutes or in the class Gammaproteobacteria isolated from a hypersaline pond in Sichuan, China. Characterization of heterotrophic prokaryote subgroups in the Sfax coastal solar salterns showed that the Alphaproteobacteria class in the non-crystallizer pond samples and the Bacteroidetes phylum in the crystallizer pond samples (Trigui et al. 2011). The different microbial genera present in the saline sediments and soils belonged mostly to halophilic bacteria, suggesting that the coast near saltern may be a valuable system to investigate saline influence the microbial community.

Yinggehai saltern is located in the southwest of Hainan Island, China. It was built in 1958, a high-salinity environment in the coastal waters. The saltern area is warm and hot all year and has very distinct wet and dry season. Evaporation is much greater than rainfall, and this superior climate condition has become a suitable place for salt drying. This study aims to explore the roles of the microbial community in the coastal soil and sediment near Yinggehai saltern by using 16S and ITS ribosomal DNA sequencing. In addition, we focus on salt-tolerance function in the microbial community of the soil and sediment. It will unravel the geographical factors affect the halotolerant bacteria community.

\section{Materials and Methods}

\section{Study Site and Sample Collection}

Yinggehai saltern is located in Hainan Island, China (Fig. 1). Three successional areas were selected for analysis, including the land zone (YGHLS, surrounded by plants, $18.4948 \mathrm{~N} 108.7158 \mathrm{E}$ ), the intertidal zone (YGHIS, ebb and flow of the tide, 18.4931N 108.7156E), and the inshore zone (YGHWS, immersed by 
seawater, $18.4898 \mathrm{~N}$ 108.7153E). The samples were collected in July 2018. Quadruplicate $1 \times 1 \mathrm{~m}^{2}$ plots were separated by $10 \mathrm{~m}$ in each area. For each plot, 5 soil cores $(5-10 \mathrm{~cm}$ diameter $\times 5-10 \mathrm{~cm}$ depth) were taken to make a composite sample.

\section{Determination of Physicochemical Characteristics}

Soil and sediment samples were air-dried and sieved through a 100-mesh sieve for determination of organic matter $(\mathrm{OM})$. Electrical conductivity $(\mathrm{EC}), \mathrm{pH}$, total nitrogen, sodium $(\mathrm{Na})$, sulfate $\left(\mathrm{S}^{-\mathrm{SO}_{4}^{2-}}\right)$, nitrate $\left(\mathrm{N}^{-\mathrm{NO}_{3}^{-}}\right)$ and ammonium $\left(\mathrm{N}-\mathrm{NH}_{4}^{+}\right.$) were sieved through a 10-mesh sieve. The physicochemical characteristics were tested according to the method described by Chen et al. (2020).

\section{Quantification of Microbial Abundance}

OMEGA Soil DNA Kit was used to extracted genomic DNA. Quantity and quality of DNA was measured by NanoDrop ND-1000 spectrophotometer (Thermo Fisher Scientific, Waltham, MA, USA) and agarose gel electrophoresis. Microbial abundance quantification was evaluated by real-time quantitative polymerase chain reaction (Xiong et al. 2017). The copy number of 16S rRNA and ITS genes was determined by five replicates of each sample with the primers 338F (5'-ACTCCTACGGGAGGCAGCA-3') and 519R (5'-ATTACCGCGGCTGCTGG-3') (Zhang et al. 2017) and the primers ITS5F (5'-GGAAGTAAAAGTCGTAACAAGG-3') and ITS1R (5'-GCTGCGTTCTTCATCGATGC-3') respectively.

\section{PCR Amplification and Sequencing}

The 16S rDNA V3-V4 region was amplified using primer 338F (5'-ACTCCTACGGGAGGCAGCA-3') and primer 806R (5'-GGACTACHVGGGTWTCTAAT-3') (Hong et al. 2020), and the ITS1 region was amplified using primer ITS5 (5'-GGAAGTAAAAGTCGTAACAAGG-3') and primer ITS2 (5'-GCTGCGTTCTTCATCGATGC-3') (White et al. 1990). The primers incorporated with sample specific 7 bp barcodes were used to perform multiplex sequencing. PCR mixtures contained $5 \mu$ of Q5 reaction buffer $(5 \times), 5 \mu \mathrm{l}$ of Q5 High-Fidelity GC buffer $(5 \times), 2 \mu$ of template, $1 \mu \mathrm{l}(10 \mu \mathrm{M})$ of each primer, $2 \mu \mathrm{l}(2.5 \mathrm{mM})$ of dNTPs, $0.25 \mu \mathrm{l}$ of Q5 High-Fidelity DNA Polymerase (5 U/ $\mu \mathrm{l})$, and $8.75 \mu \mathrm{l}$ of $\mathrm{ddH}_{2} \mathrm{O}$. Reactions were programmed for a denaturation at $98{ }^{\circ} \mathrm{C}$ for $2 \mathrm{~min}$, followed by 25 cycles consisting of $98{ }^{\circ} \mathrm{C}$ for $15 \mathrm{~s}, 55^{\circ} \mathrm{C}$ for $30 \mathrm{~s}$, and $72{ }^{\circ} \mathrm{C}$ for $30 \mathrm{~s}$, with an extension of $5 \mathrm{~min}$ at $72{ }^{\circ} \mathrm{C}$. PCR products were purified and quantified with Agencourt AMPure Beads (Beckman Coulter, Indianapolis, IN) and the PicoGreen dsDNA Assay Kit 
(Invitrogen, Carlsbad, CA, USA) separately. Products were pooled in equal amounts, and sequencing was performed using the Illumina MiSeq platform at Shanghai Personal Biotechnology Co., Ltd.

\section{Sequence Analysis}

QIIME v1.8.0 was used for the sequencing data process (Caporaso et al. 2010). Valid sequences were identified based on raw sequencing reads with exact matches to the barcodes. Paired-end reads assembled using FLASH (Magoc and Salzberg, 2011). The high-quality sequences were assigned to operational taxonomic units (OTUs) by UCLUST with a 97\% similarity threshold (Edgar 2010). Representative microbial sequences were selected from each OTU using default parameters, and matched against the SILVA and UNITE databases, respectively. It discarded the OTUs containing less than $0.001 \%$ of total sequences across all samples. An averaged, rounded rarefied OTU table was generated by averaging 100 evenly resampled OTU subsets under $90 \%$ of the minimum sequencing depth to minimize the difference in sequencing depth across samples.

\section{Bioinformatics and Statistical Analysis}

Chao1 richness estimator, Shannon diversity index, Simpson index, and ACE metric (abundance-based coverage estimator) were estimated using the OTU table in QIIME. Beta diversity analysis was performed using UniFrac distance metrics (Lozupone and Knight, 2005; Lozupone et al. 2006) and visualized via principal coordinate analysis (PCoA). Significant differences in microbial structures were evaluated based on analysis of similarity (ANOSIM) performed by the R package "vegan" (v3.2.0) (Clarke 1993). Venn diagrams were generated using the R package "VennDiagram" (Zaura et al. 2009). The linear regression analysis was conducted with Origin v 9.1. PICRUSt2 analysis was performed to gain insight for the salt-tolerance function (Langille et al. 2013). The gene family counts for each sample were derived from the KEGG ortholog (KO).

\section{Sequence Accession Numbers}

The raw sequence data are available in the NCBI Sequence Read Archive (SRA) database under the accession numbers PRJNA699381 and PRJNA699383.

\section{Results}

\section{Site Characteristics}

The selected sampling sites were from the land zone to the inshore zone, which is nearby Yinggehai saltern. 
The variations of a wide range of physicochemical factors were observed. This analysis could reflect the ecosystem nearby the saltern zone (Table S1). The $\mathrm{NH}_{4}^{+}-\mathrm{N}$ of the samples from the three sites did not vary much. The YGHWS sample had significant (Duncan test, $P<0.05)$ higher sodium $(2338.47 \pm 78.58 \mathrm{mg} / \mathrm{kg}$ ) and sulfate $(187.35 \pm 8.50 \mathrm{mg} / \mathrm{kg})$ contents. Detailed descriptions of the data are provided in Supplementary Table S1.

\section{Microbial Community Diversity and Structure}

The microbial communities could be adequately represented by the observed OTUs based on the relatively stable rarefaction curves (Fig. S1). Statistical results demonstrated that the most diversity indices were significantly different among the three sampling points at bacterial and fungal communities (Table 1). Although Shannon, evenness, and simpson index of bacterial community were not significantly different among the three sampling points, the other two diversity indices were significantly related to each other. Venn diagrams showed that the unique bacterial OUTs in the YGHLS, YGHIS, and YGHWS were 2118, 1587 and 2416, the unique fungal OUTs in the YGHLS, YGHIS, and YGHWS were 775, 716 and 1351 (Fig. S2). The difference in soil microbial communities across the samples was showed by PCoA (Fig. 2). ANOSIM analysis (Bray-Curtis) revealed that the three samples were separated from each other (Table S2, YGHWS vs YGHIS vs YGHLS, $P<0.05$ ). In bacteria, YGHWS samples were not separated from group of the other two samples based on Bray-Curtis analysis (ANOSIM, YGHWS vs YGHIS and YGHLS, $P>0.05$ ). Similarly, the fungi of YGHIS samples clustered tightly together with YGHLS and YGHWS group (ANOSIM, YGHIS vs YGHWS and YGHLS, $P>0.05$ ).

\section{Microbial Community Composition}

The taxonomy of the bacterial community at the phylum and genus levels is presented in Fig. 3A and Fig. 3B. Proteobacteria, Actinobacteria, Acidobacteria, Chloroflexi, and Gemmatimonadetes were the five most abundant phyla in all samples in decreasing order and accounted for $84.41 \pm 3.23 \%$ of the total microbial community. Halomonas and Halobacillus presented in the samples and accounted for $0.0335 \pm 0.0586 \%$ and $0.0241 \pm 0.0304 \%$ of the total microbial community, respectively. The identified phyla and genera of samples from the three sites were shown in Fig. 3A and Fig. 3B. Furthermore, the samples from three sites clustered independently in the bacterial genus distribution (Fig. S 3A).

Furthermore, we analyzed the relative abundance of fungi in the three samples at the phylum and genus 
levels. The fungal phyla Ascomycota, Basidiomycota, Ciliophora, Zygomycota, Cercozoa, and Chytridiomycota were more abundant (Fig. 3C). Schizophyllum, Bullera, Cryptococcus, Talaromyces, Aspergillus, Tomentella, Spiromastix, and Auricularia were detected in all the samples (Fig. 3D). A rare genus Wallemia presented in the samples and accounted for $0.0308 \pm 0.0445 \%$ of the total microbial community. The patterns of fungal genus distribution are showed in Fig. S 3B.

\section{Relationship between Physicochemical Characteristics and Abundance of Halophilic} Bacteria and Fungi

Sodium and sulphate were selected from our initial physicochemical indicators in the linear model, showing that they did not have linear relationships with Halobacillus and Wallemia (Fig. 4). However, a bacterial genus Halomonas showed positive relationship with sodium $\left(\mathrm{R}^{2}=0.501, P<0.05\right)$ and sulphate $\left(\mathrm{R}^{2}=0.494\right.$, $P<0.05)$ content. It indicated that the sodium and sulphate content significantly affected the Halomonas relative abundance, whereas they did not relate to Halobacillus and Wallemia.

\section{Relationship between Microbial Indicators and Halophilic Bacteria Abundance}

The structure (weighted PCoA1) and richness were selected as microbial indicators in the linear model, as they could explain the relationship with halophilic bacteria abundance. As a result, bacterial weighted PCoA1 $\left(\mathrm{R}^{2}=0.065, P>0.05\right)$ and richness $\left(\mathrm{R}^{2}=0.118, P>0.05\right)$ did not show linear relationships with Halobacillus and Halomonas abundance respectively. However, we found that bacterial weighted PCoA1 $\left(\mathrm{R}^{2}=0.393, P<\right.$ 0.05) had a significant positive relationship with Halomonas abundance. Similarly, we also found that bacterial richness $\left(\mathrm{R}^{2}=0.348, P<0.05\right)$ had a significant positive relationship with Halobacillus abundance (Fig. 5).

\section{Bacterial function prediction}

The salt-tolerance functional profile of composting microbiota was predicted by PICRUSt depending on KEGG database. Relative abundance of $\mathrm{Na}^{+}: \mathrm{H}^{+}$antiporter, Trk system potassium uptake protein and Kdp operon response regulator in the samples exceed $0.02 \%, 0.09 \%$, and $0.06 \%$ respectively (Fig. 6). Specifically, $\mathrm{Na}^{+}: \mathrm{H}^{+}$antiporter ranged from $0.000398 \pm 0.00009 \%$ to $0.0235 \pm 0.00228 \%$ at YGHLS samples, from $0.00162 \pm 0.000725 \%$ to $0.02394 \pm 0.00209 \%$ at YGHIS samples, and from $0.00129 \pm 0.00154 \%$ to 0.01726 $\pm 0.00237 \%$ at YGHWS samples. Other salt-tolerance Trk system potassium uptake protein ranged from 
$0.03924 \pm 0.00158 \%$ to $0.07783 \pm 0.00369 \%$ at YGHLS samples, from $0.04028 \pm 0.00442 \%$ to $0.07283 \pm$ $0.00524 \%$ at YGHIS samples, and from $0.04772 \pm 0.013 \%$ to $0.04958 \pm 0.0023 \%$ at YGHWS samples. Furthermore, Kdp operon response regulator ranged from $0.05131 \pm 0.000778 \%$ to $0.06426 \pm 0.00501 \%$ at YGHLS samples, from $0.04603 \pm 0.00422 \%$ to $0.05506 \pm 0.00962 \%$ at YGHIS samples, and from $0.03306 \pm$ $0.00228 \%$ to $0.03487 \pm 0.0033 \%$ at YGHWS samples.

\section{Discussion}

Proteobacteria, Bacteroidetes, Chloroflexi, and Firmicutes dominated the bacterial communities of sediment samples present near the Mediterranean Sea coast of Camargue, while members belonging to Proteobacteria, Bacteroidetes, Gemmatimonadetes, Actinobacteria, Firmicutes, and Acidobacteria dominated the bacterial communities of the soil samples (Osman et al. 2018). In this study, Proteobacteria, Actinobacteria, Acidobacteria, Chloroflexi and Gemmatimonadetes were the five most abundant phyla in the samples. Pomorie salterns and Burgas salterns located at Burgas Bay, Black Sea coast, Bulgaria. And, bacterial genera Halomonas was isolated from the two salterns (Boyadzhieva et al. 2018). Other genera Salimicrobium, Halalkalibacillus, Virgibacillus, Alkalibacillus, Marinococcus, Halobacillus, Halomonas, Idiomarina, Chromohalobacter, and Halovibrio were obtained from a hypersaline pond in Sichuan, China (Tang et al. 2011). Fungal genera Wallemia ichthyophaga have been isolated globally from natural hypersaline environments (Zalar et al. 2005; Gunde-Cimerman et al. 2009). Halomonas, Halobacillus and Wallemia were also found in this study. It indicated that bacterial and fungal community composition located in Yinggehai coastal soil and sediment were similar with other hypersaline environments.

The observed shifts in salt tolerance along the gradients indicate that salinity environmental factors had shaped trait distributions and filtered the microbial communities. Previous studies revealed that physicochemical factors, such as, $\mathrm{pH}$, salinity, exchangeable cations, $\mathrm{C} / \mathrm{N}$ ratio, OM content, and sulfate content, they were major drivers that affected microbial community structure and function in the soil and sediment samples (Jorgensen et al. 2012; Dini-Andreote et al. 2014; Zeglin et al. 2016; Verma et al. 2017; Kang et al. 2018; Canini et al. 2020). Sodium and sulfate in the YGHWS sample showed significantly higher than the samples from other two site. Furthermore, the samples from three sites separated from each other in the weighted and unweighted UniFrac distances. Typically, content of sodium and sulphate showed a significantly positive relationship with halophilic bacteria Halomonas abundance. It revealed that the 
halophilic bacteria abundance of coastal soils and sediments present near saltern field was possibly influenced by the soil physicochemical characteristics. However, Halobacillus and Wallemia did not show linear relationships with sodium and sulphate. The influence was obviously limited to the specific genus Halomonas. Interestingly, the bacterial weighted PCoA1 had a significant positive relationship with Halomonas abundance. Thus, Halomonas abundance was directly influenced by physicochemical characteristics or bacterial weighted PCoA1? It still needs more studies to ascertain.

The $\mathrm{Na}^{+} / \mathrm{H}^{+}$antiporter is ubiquitous from bacteria to mammals and plays an important role in extrusion of $\mathrm{Na}^{+}$or $\mathrm{Li}^{+}$in exchange for $\mathrm{H}^{+}$to keep the cytoplasm isosmotic with the environment and to avoid intoxication of living cells (Yang et al. 2006). At a high external salt concentration, bacteria take up $\mathrm{K}^{+}$from the surrounding medium and accumulate $\mathrm{K}^{+}$as an osmoregulatory solute to achieve an osmotic equilibrium. The major transport systems for $\mathrm{K}^{+}$accumulation in these organisms is the transporter Kdp, the Ktr system, and the Trk transporter (Kraegeloh et al. 2005). Relative abundance of Trk transporter was higher than $\mathrm{Na}^{+}: \mathrm{H}^{+}$ antiporter and Kdp transporter in the samples. It indicated that the halotolerant bacteria of Yinggehai coastal soil and sediment mainly take the Trk system in response to $\mathrm{Na}^{+}$osmotic stress.

Acknowledgements This work was supported by Key Research and Development Projects of Hainan Province (ZDYF2019212), Natural Science Foundation of Hainan Province (318MS072) and Projects of Key Laboratory of Utilization and Conservation for Tropical Marine Bioresources, Ministry of Education (UCTMB20205).

\section{Compliance with ethical standards}

Conflict of Interest The authors declare that they have no conflict of interest.

\section{References}

Boyadzhieva I, Tomova I, Radchenkova N, Kambourova M, Poli A, Vasileva-Tonkova E (2018) Diversity of heterotrophic halophilic bacteria isolated from coastal solar salterns, Bulgaria and their ability to synthesize bioactive molecules with biotechnological impact. Microbiology 87(4):519-528

Caporaso JG, Kuczynski J, Stombaugh J, Bittinger K, Bushman FD, Costello EK, Fierer N, Peña AG, Goodrich JK, Gordon JI, Huttley GA, Kelley ST, Knights D, Koenig JE, Ley RE, Lozupone CA, 
McDonald D, Muegge BD, Pirrung M, Reeder J, Sevinsky JR, Turnbaugh PJ, Walters WA, Widmann J, Yatsunenko T, Zaneveld J, Knight R (2010) QIIME allows analysis of high-throughput community sequencing data. Nat Meth 7:335-336

Canini F, Geml J, D'Acqui LP, Selbmann L, Onofri S, Ventura S, Zucconi L (2020) Exchangeable cations and $\mathrm{pH}$ drive diversity and functionality of fungal communities in biological soil crusts from coastal sites of Victoria Land, Antarctica. Fungal Ecol 45:100923

Chen YG, Zhang ZH, Luo HW, Li Z, Zhang LJ, Huang H (2020) Distinct characteristics of bacterial community in the soil of Nanshazhou Island, South China Sea. Curr Microbiol 77:1292-1300

Clarke KR (1993) Non-parametric multivariate analyses of changes in community structure. Austral Ecol $18: 117-143$

Dini-Andreote F, Silva MCP, Triadó-Margarit X, Casamayor EO, van Elsas JD, Salles JF (2014) Dynamics of bacterial community succession in a salt marsh chronosequence: evidences for temporal niche partitioning. ISME J 8:1989-2001

Edgar RC (2010) Search and clustering orders of magnitude faster than BLAST. Bioinformatics 26:24602461

Gunde-Cimerman N, Ramos J, Plemenitas A (2009) Halotolerant and halophilic fungi. Mycol Res 113:12311241

Hong YH, Huang Y, Wu S, Yang XZ, Dong YZ, Xu DY, Huang ZQ (2020) Effects of imidacloprid on the oxidative stress, detoxification and gut microbiota of Chinese mitten crab, Eriocheir sinensis. Sci Total Environ 729:138276

Jorgensen SL, Hannisdal B, Lanzén A, Baumberger T, Flesland K, Fonseca R, Øvreås L, Steena IH, Thorseth IH, Pedersen RB, Schleper C (2012) Correlating microbial community profiles with geochemical data in highly stratified sediments from the Arctic Mid-Ocean Ridge. Proc Natl Acad Sci 109:2846-2855

Kang HZ, Gao HH, Yu WJ, Yi Y, Wang Y, Ning ML (2018) Changes in soil microbial community structure and function after afforestation depend on species and age: Case study in a subtropical alluvial island. Sci Total Environ 625:1423-1432 
Kraegeloh A, Amendt B, Kunte HJ (2005) Potassium transport in a halophilic member of the Bacteria domain: identification and characterization of the $\mathrm{K}^{+}$uptake systems TrkH and TrkI from Halomonas elongata DSM 2581 ${ }^{\mathrm{T}}$. J Bacterial 187(3):1036-1043

Langille MGI, Zaneveld J, Caporaso JG, McDonald D, Knights D, Reyes JA, Clemente JC, Burkepile DE, Thurber RLV, Knight R, Beiko RG, Huttenhower C (2013) Predictive functional profiling of microbial communities using 16S rRNA marker gene sequences. Nat Biotechnol 31:814-821

Lozupone C, Hamady M, Knight R (2006) UniFrac-an online tool for comparing microbial community diversity in a phylogenetic context. BMC Bioinform 7:371

Lozupone C, Knight R (2005) UniFrac: a new phylogenetic method for comparing microbial communities. Appl Environ Microbiol 71:8228-8235

Magoc T, Salzberg SL (2011) FLASH: fast length adjustment of short reads to improve genome assemblies. Bioinformatics 27:2957-2963

Ng ZY, Tan GYA (2018) Selective isolation and characterisation of novel members of the family Nocardiopsaceae and other actinobacteria from a marine sediment of Tioman Island. Anton Leeuw Int J G 111(5):727-742

Osman JR, Regeard C, Badel C, Fernandes G, DuBow MS (2019) Variation of bacterial biodiversity from saline soils and estuary sediments present near the Mediterranean Sea coast of Camargue (France). Anton Leeuw Int J G 112(3):351-365

Somboonna N, Assawamakin A, Wilantho A, Tangphatsornruang S, Tongsima S (2012) Metagenomic profiles of free-living archaea, bacteria and small eukaryotes in coastal areas of Sichang island, Thailand. BMC Genomics 13:S29

Sottorff I, Wiese J, Imhoff JF (2019) High diversity and novelty of Actinobacteria isolated from the coastal zone of the geographically remote young volcanic Easter Island, Chile. Int Microbiol 22(3):377-390

Tang J, Zheng AP, Bromfield ESP, Zhu J, Li SC, Wang SQ, Deng QM, Li P (2011) 16S rRNA gene sequence analysis of halophilic and halotolerant bacteria isolated from a hypersaline pond in Sichuan, China. Ann Microbiol 61:375-381

Trigui H, Masmoudi S, Brochier-Armanet C, Barani A, Grégori G, Denis M, Dukan S, Maalej S (2011) Characterization of heterotrophic prokaryote subgroups in the Sfax coastal solar salterns by combining 
flow cytometry cell sorting and phylogenetic analysis. Extremophiles 15:347-358

Verma P, Raghavan RV, Jeon CO, Lee HJ, Priya PV, Dharani G, Kirubagaran R (2017) Complex bacterial communities in the deep-sea sediments of the Bay of Bengal and volcanic Barren Island in the Andaman Sea. Mar Genomics, 31:33-41

White TJ, Bruns T, Lee S, Taylor JW (1990) Amplification and direct sequencing of fungal ribosomal RNA genes for phylogenetics. In: Innis MA, Gelfand DH, Sninsky JJ, White TJ (eds) PCR protocols: A guide to methods and applications. Academic Press, New York. 1990, 315-322

Xiong W, Li R, Ren Y, Liu C, Zhao Q, Wu H, Jousset A, Shen QR (2017) Distinct roles for soil fungal and bacterial communities associated with the suppression of vanilla Fusarium wilt disease. Soil Biol Biochem 107:198-207

Yang LF, Jiang JQ, Zhao BS, Zhang B, Feng DQ, Lu WD, Wang L, Yang SS (2006) $\mathrm{A} \mathrm{Na}^{+} / \mathrm{H}^{+}$antiporter gene of the moderately halophilic bacterium Halobacillus dabanensis D-8T: cloning and molecular characterization. FEMS Microbiol Lett 255:89-95

Zalar P, de Hoog GS, Schroers HJ, Frank JM, Gunde-Cimerman N (2005) Taxonomy and phylogeny of the xerophilic genus Wallemia (Wallemiomycetes and Wallemiales, cl. et ord. nov.). Anton Leeuw Int J G 87(4): $311-328$

Zaura E, Keijser BJF, Huse SM, Crielaard W (2009) Defining the healthy "core microbiome" of oral microbial communities. BMC Microbiol 9:259

Zeglin LH, Wang B, Waythomas C, Rainey F, Talbot SL (2016) Organic matter quantity and source affects microbial community structure and function following volcanic eruption on Kasatochi Island, Alaska. Environ Microbiol 18:146-158

Zhang XM, Zhang Q, Liang B, Li JL (2017) Changes in the abundance and structure of bacterial communities in the greenhouse tomato cultivation system under long-term fertilization treatments. Appl Soil Ecol 121:82-89 


\section{Figures}

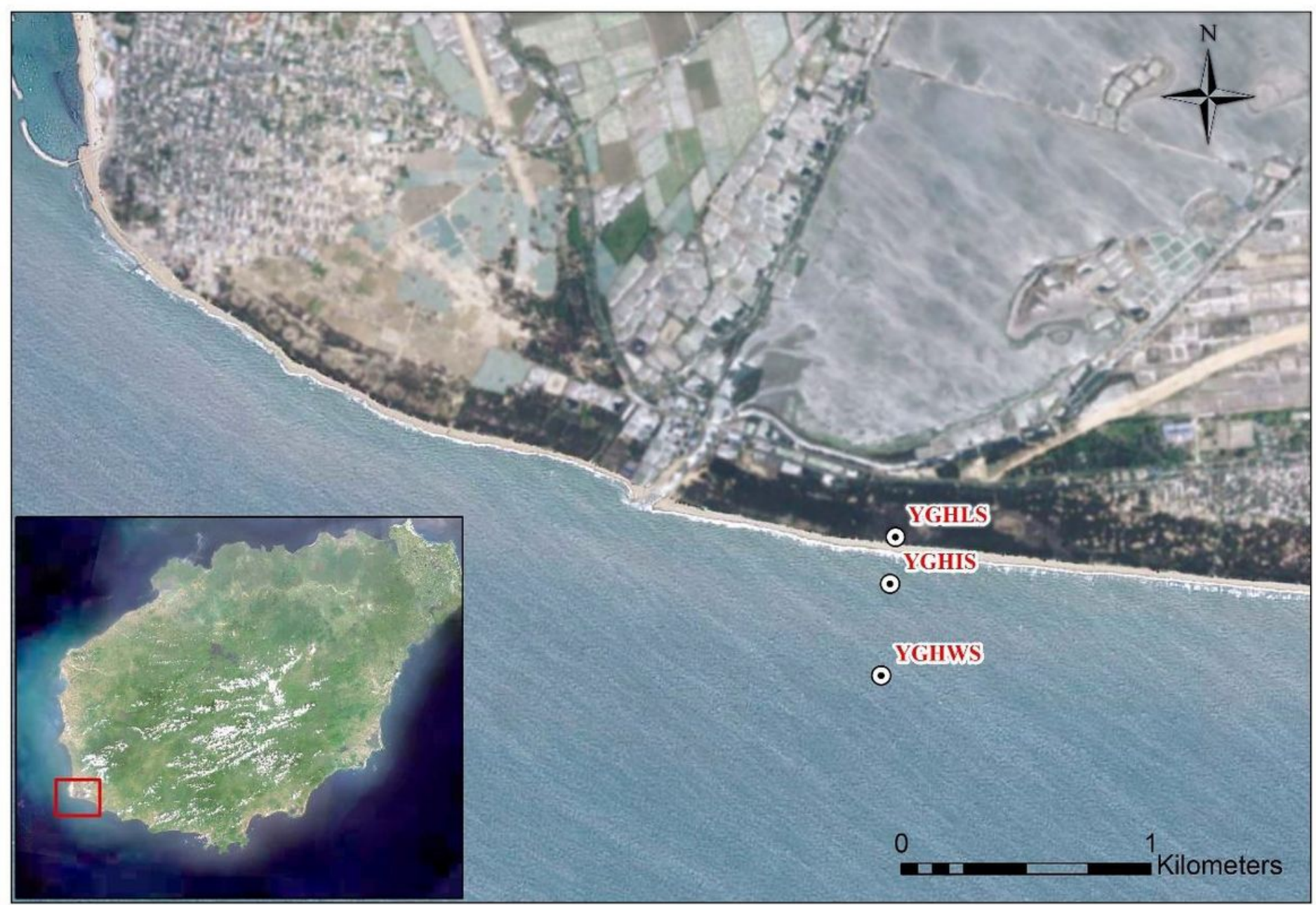

\section{Figure 1}

Geographic Information System map of sample sites. Note: The designations employed and the presentation of the material on this map do not imply the expression of any opinion whatsoever on the part of Research Square concerning the legal status of any country, territory, city or area or of its authorities, or concerning the delimitation of its frontiers or boundaries. This map has been provided by the authors. 

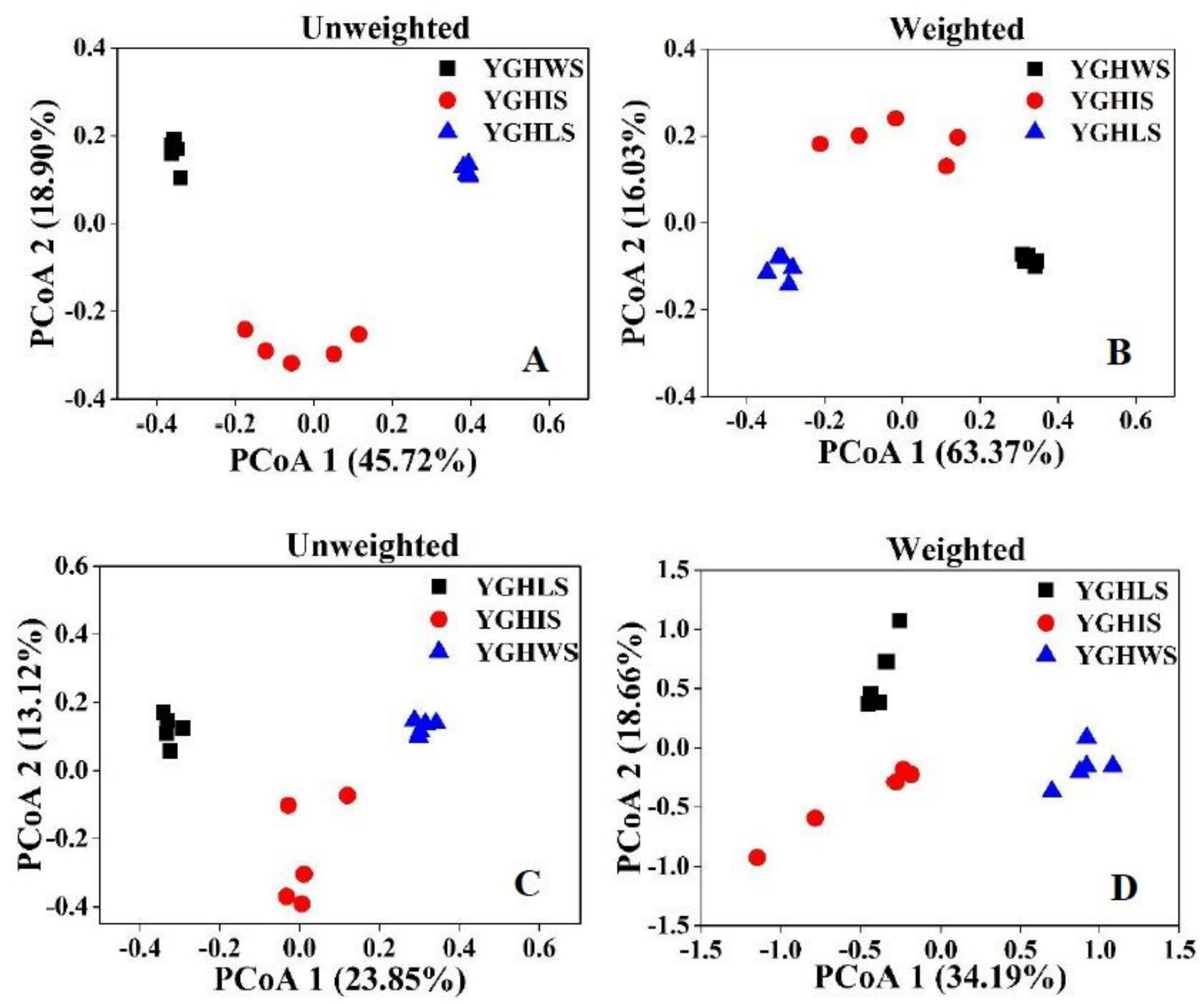

Figure 2

Microbial community structures in the soil and sediment from Yinggehai saltern coast. UniFracunweighted (A) and uniFrac-weighted (B) principle coordinate analysis of bacterial community structures, UniFrac-unweighted (C) and uniFrac-weighted (D) principle coordinate analysis of fungal community structures. 
A

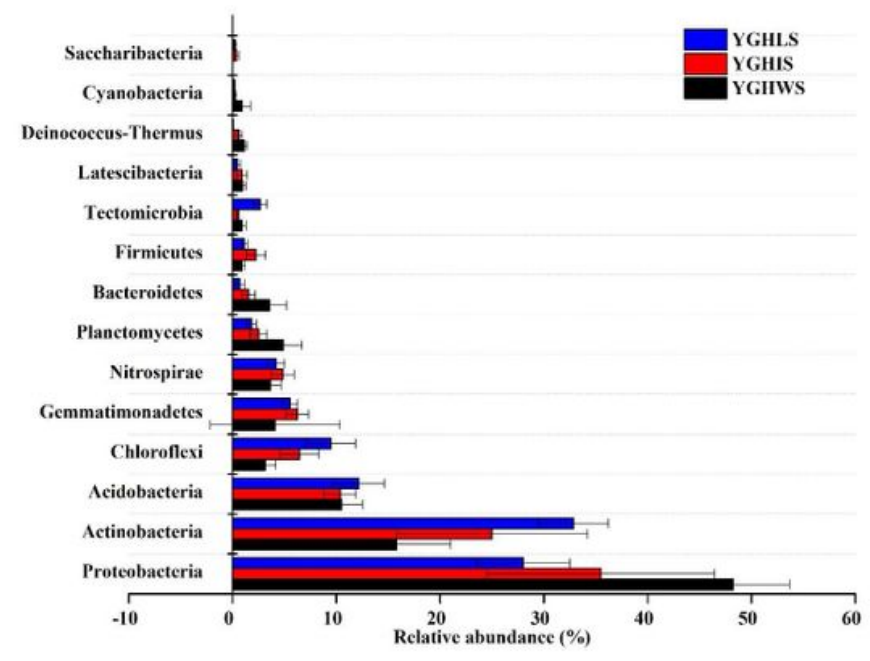

C

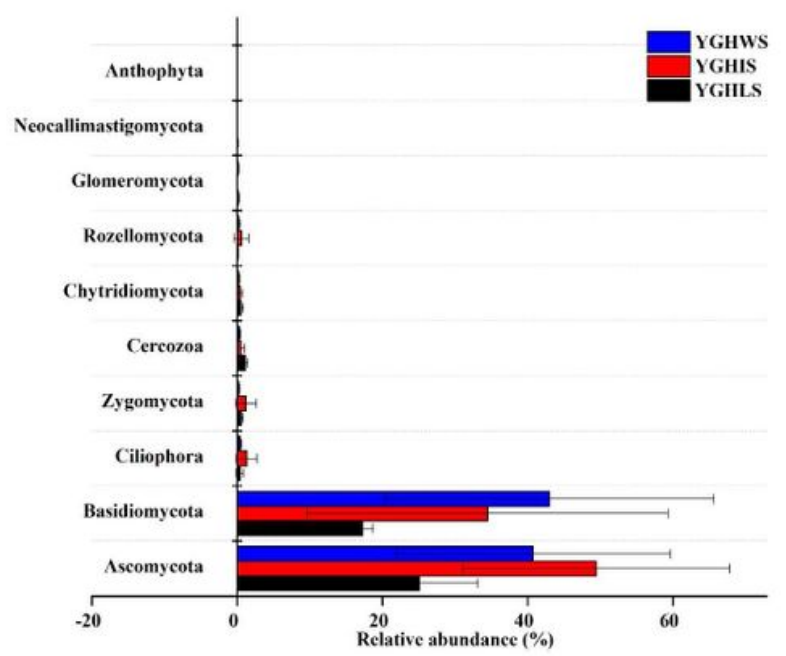

B

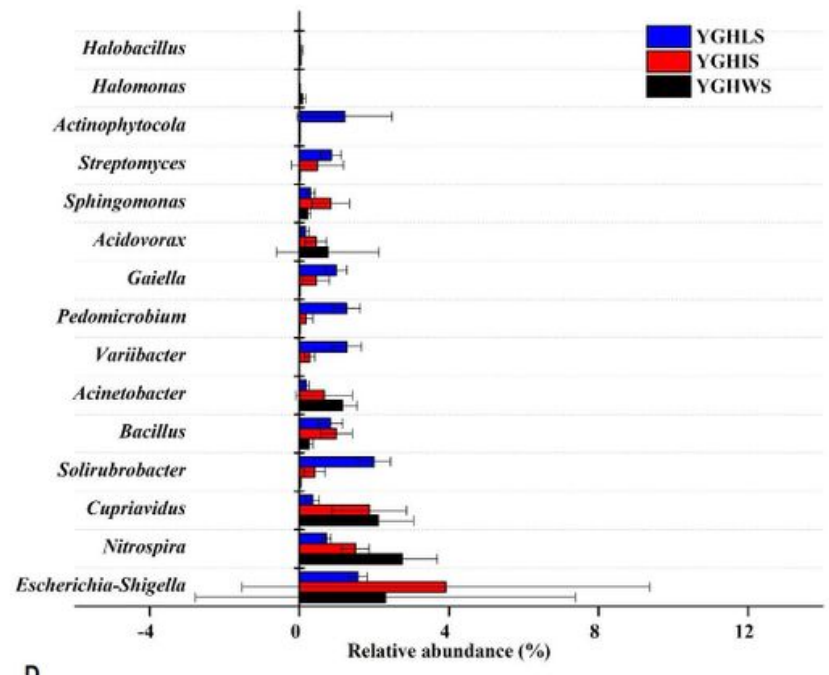

D

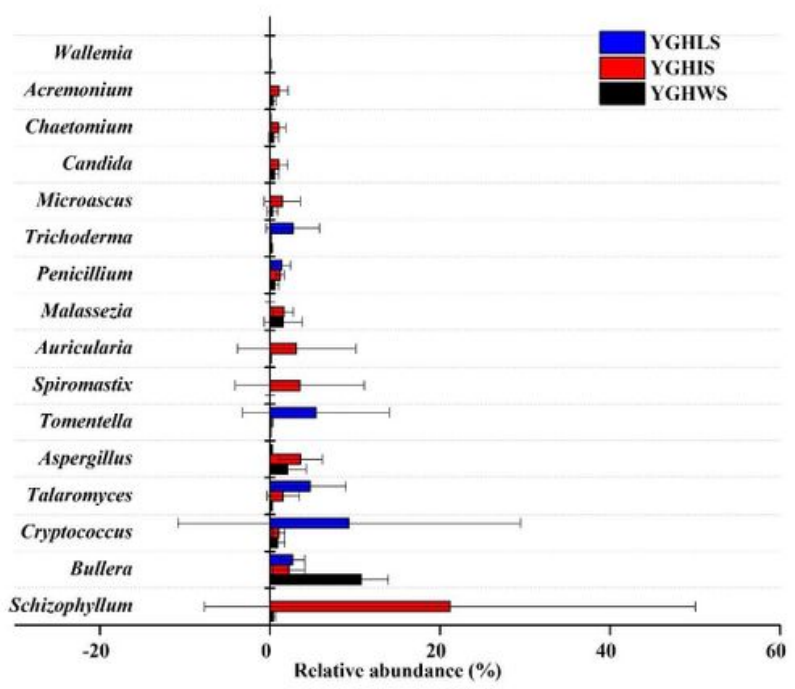

\section{Figure 3}

Relative abundances of the microbial taxon in the soil and sediment from Yinggehai saltern coast. The bacterial phylum (A) and genera (B); and the fungal phylum (C) and genera (D). Bars represent the standard deviation of the 5 replicates. 

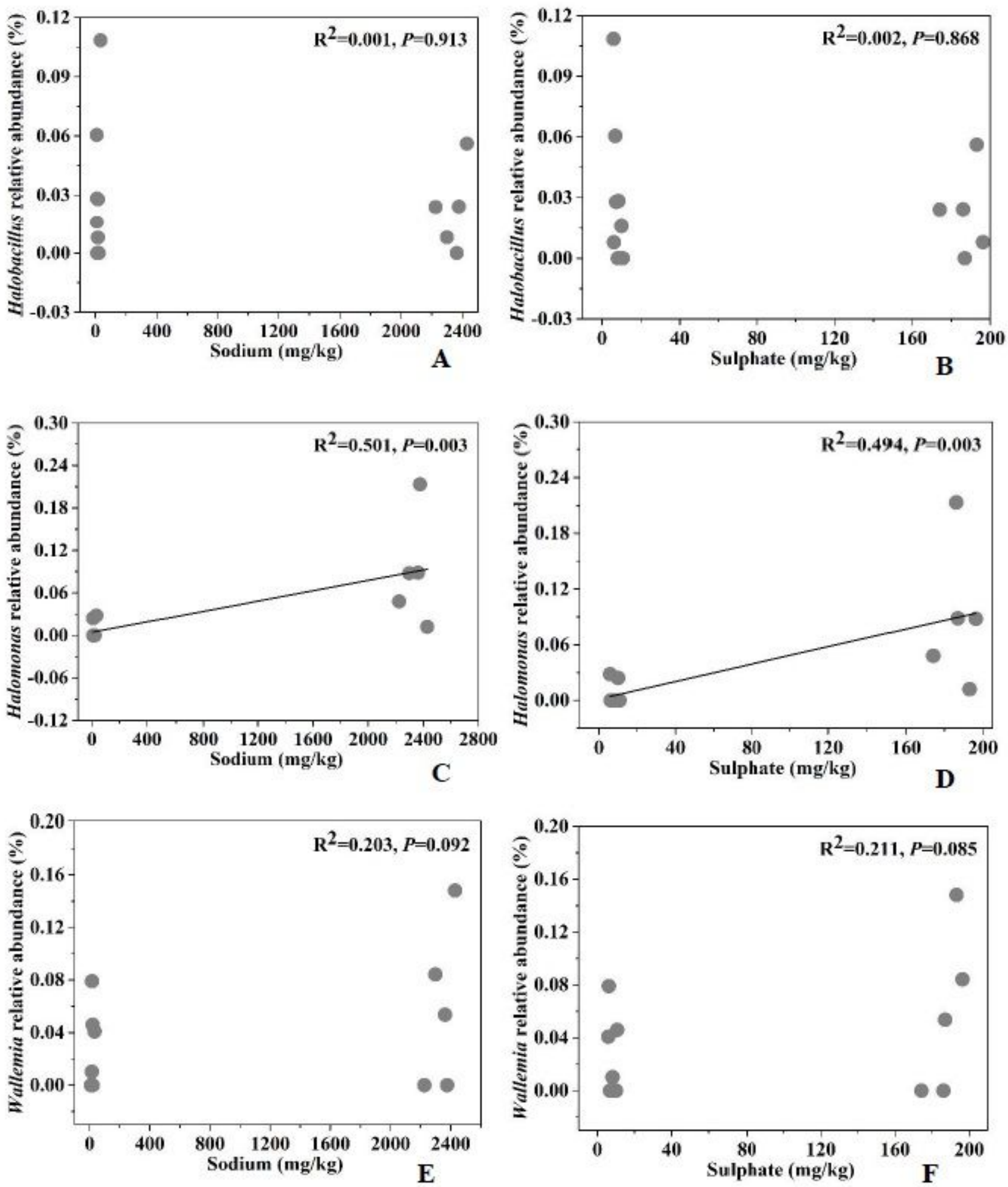

\section{Figure 4}

The linear regression relationship between sodium content and Halobacillus relative abundance (A), sulphate content and Halobacillus relative abundance (B), sodium content and Halomonas relative abundance (C), sulphate content and Halomonas relative abundance (D), sodium content and Wallemia relative abundance $(E)$, sulphate content and Wallemia relative abundance $(F)$. 

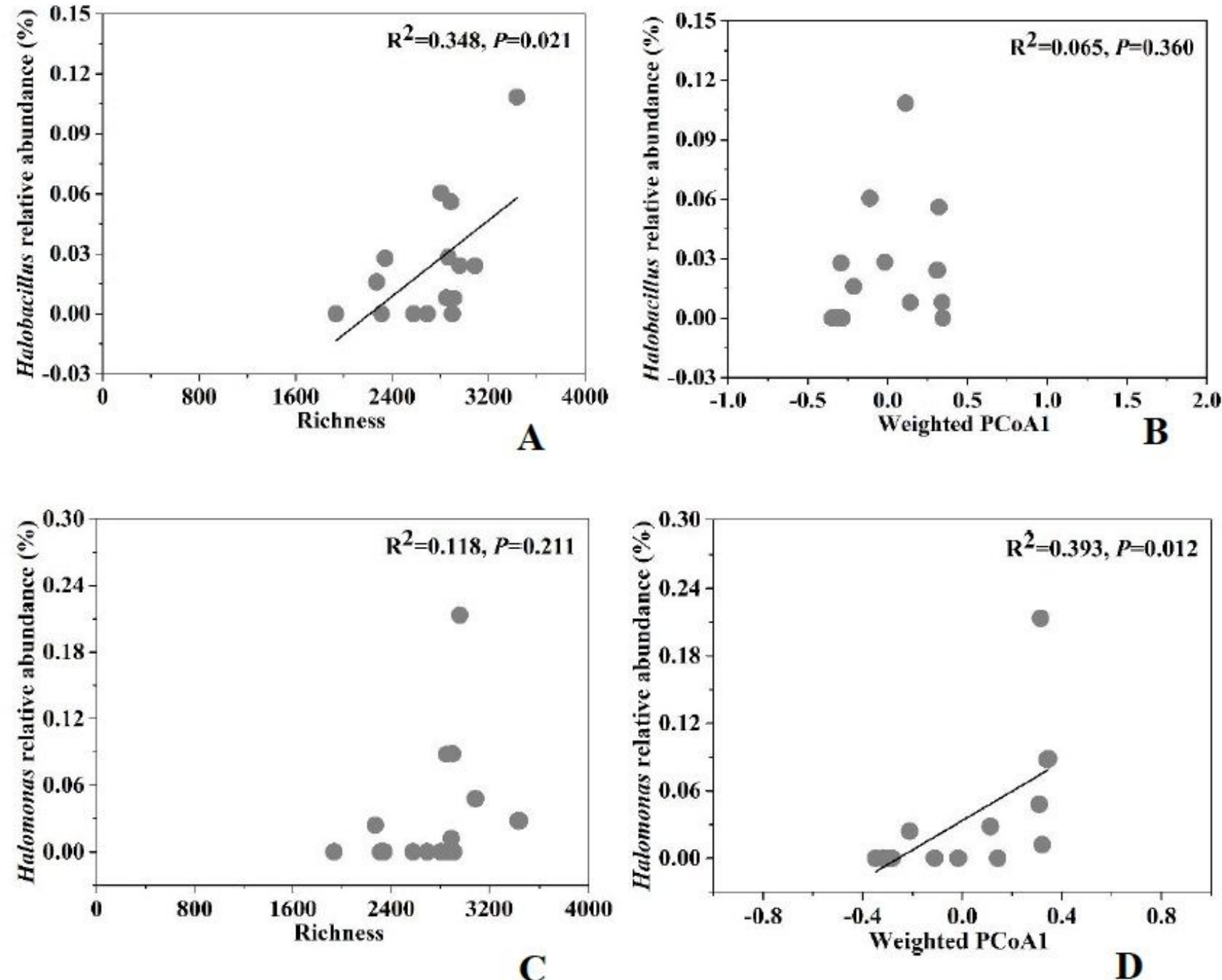

\section{Figure 5}

The linear regression relationship between bacterial richness and Halobacillus relative abundance $(A)$, bacterial structure and Halobacillus relative abundance (B), bacterial richness and Halomonas relative abundance (C), bacterial structure and Halomonas relative abundance (D). 
A

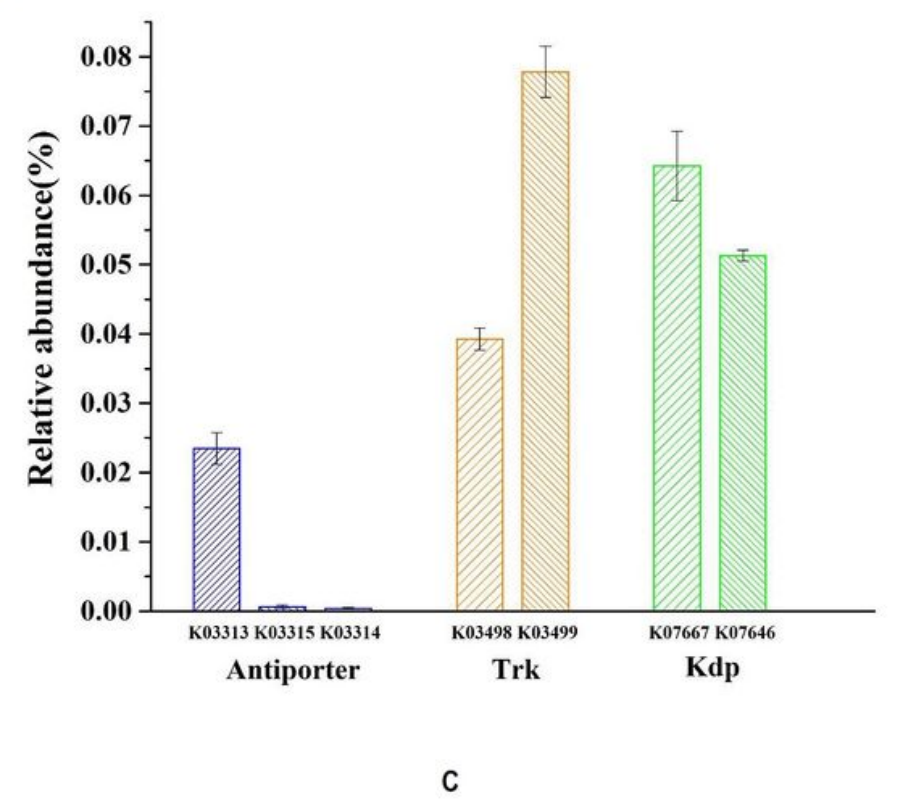

B

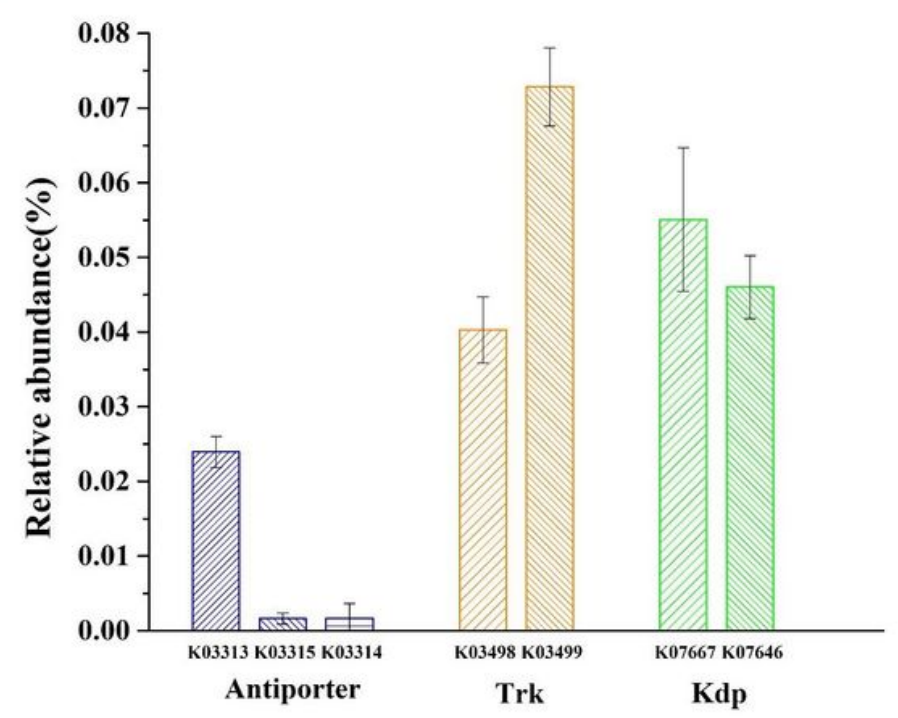

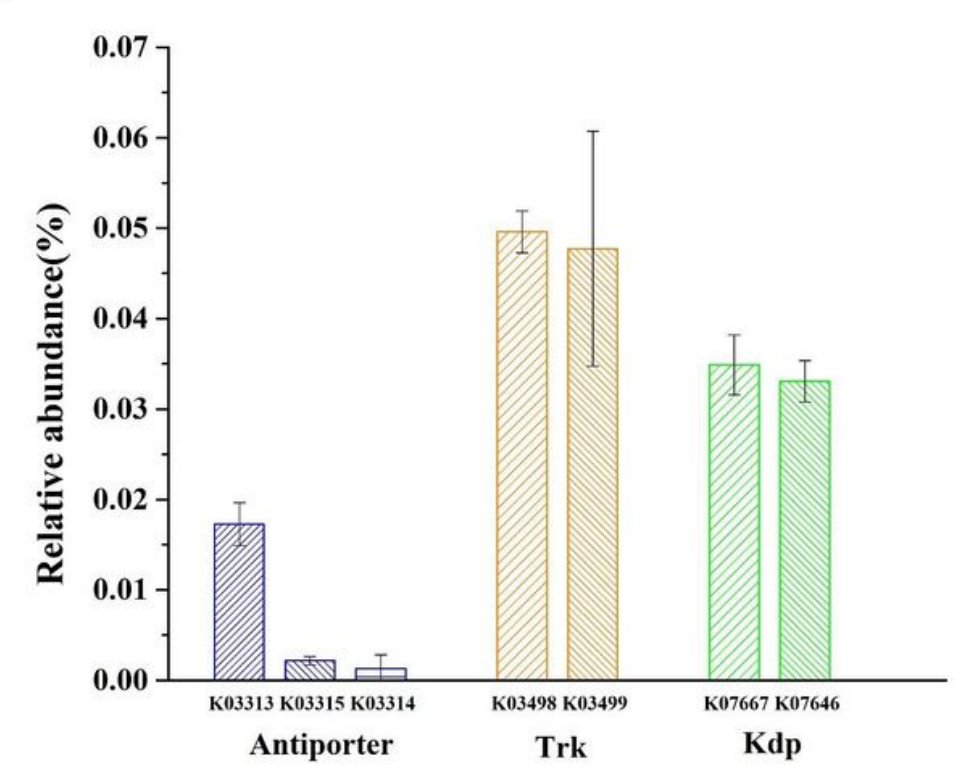

Figure 6

Proportion of the predicted $\mathrm{Na}+$ transport pathway. $\mathrm{Na}+\mathrm{H}+$ antiporter $(\mathrm{A})$, Trk system potassium uptake protein (B) and KDP operon response regulator (C).

\section{Supplementary Files}

This is a list of supplementary files associated with this preprint. Click to download.

- Table.pdf

- SupplementaryMaterials.pdf 